\title{
Examining Incentives and Preferential Treatment of Carpools on Managed Lane Facilities
}

David Ungemah, Ginger Goodin, Casey Dusza, Texas Transportation Institute Mark Burris, Texas A\&M University

\begin{abstract}
As managed lanes $(M L)$ are considered throughout more than 25 North America cities, there is a need for guidance in defining the role of carpools in tolled ML and the trade-offs between carpool exemptions and other project objectives. Increasingly, project objectives are reflecting not only mobility concerns but the need to generate revenue as well. As a result, allowing exempt or discounted users, such as carpools on priced-ML requires an evaluation of revenue impacts as well as mobility interests such as person movements, operations, and emissions.

This article highlights the existing body of knowledge regarding carpooling, facilities, and incentives designed to encourage carpooling and carpooling's contributions to society. Following a review of literature, state and regional entities involved in either operating existing ML facilities or planning for new facilities were interviewed to determine the rationale for setting their carpool policies.
\end{abstract}

\section{Introduction}

The concept of tolling on managed lanes $(\mathrm{ML})$ has evolved since the first iterations in the early 1990s. Initially conceived as the allowance of previously prohibited vehicles to high occupancy vehicle (HOV) lanes in exchange for the payment of a 
fee, otherwise known as high occupancy/toll (HOT) lanes, ML have expanded in scope to include a variety of implementations, without any inherent policy regarding HOVs.

Of particular interest are those implementations that feature the collection of toll revenue in return for use of the ML facility. Originally perceived under one of two applications-HOT lanes or express toll lanes (ETL) - ML are studied and implemented with many operational variants. The broad definition of ML not only includes these variants, but any application that involves system-management techniques such as time-of-day restrictions, vehicle-type restrictions, and value pricing. In addition to HOT lanes and ETL facilities, common types of ML in the United States are HOV lanes, truck-designated lanes, and limited-access express lanes.

Of these, HOV lanes have a longer history of operations in North America than HOT lanes and ETL facilities. First implemented on Virginia's Shirley Highway (I$395)$ in 1969 as an exclusive busway, the concept of HOV lanes was born when four-or-more person carpools and vanpools were permitted access to the facility in 1973. Initiated during a time of high fuel costs, fuel shortages throughout the United States, and public concerns regarding mobility, HOV lanes provided yet another incentive to carpool or vanpool. Although the magnitude of travel-time savings offered by HOV lanes has been studied, the role of HOV-lane-related incentives relative to other incentives to carpool has rarely received the same attention. Nationally, since 1993, vehicle miles traveled (VMT) have increased 25 percent, while the percentage use and absolute number of carpools and vanpools for commute trips has declined to a 30-year low-10,057,000 trips in 2003, down from 11,852,000 in 1993 (Bureau of Transportation Statistics 2005). In the same 10-year time frame, $\mathrm{HOV}$-lane miles have more than doubled, from approximately 1,300 lane miles in 1995 to more than 2,500 in 2000, and 3,100 in 2005. The majority of these HOV-lane miles are located in California (1,000), Georgia (400), and Texas (300) (Fuhs and Obenberger 2002).

In many ways, HOV lanes are selling an uncongested carpool trip in the HOV facility against the possibility of recurring congestion in adjacent general-purpose lanes. The expectation, in return for accepting inconvenience associated with the trip, is that the use of the HOV lane will provide some travel-time savings. As a result, carpooling rates have increased significantly within HOV corridors (more than $100 \%$ ) even as carpool rates nationwide have declined (30\%) during the past two decades (Stockton 1999). However, severe congestion in the general-purpose lanes have tended to cause animosity on the part of the general public toward 
HOV lanes if they are underutilized (Fuhs and Obenberger 2002). As a means of mitigating the "empty lane syndrome," HOT lanes have been promoted as an effective way of utilizing the excess capacity without yielding the HOV lanes' travel time advantages (Swisher 2002).

In addition to HOT lanes, which imply maintenance of HOV operations, ETL concepts have also been promoted as a means of enhancing mobility within congested corridors and regions. First implemented in Orange County, California, as the privately built and operated State Route 91 (SR-91) express toll corridor, ETL facilities provide the same benefits of HOT lanes (exclusive right-of-way with congestion-free trips along the length of the corridor), but they do not carry the same implied benefit to carpools and vanpools. The SR-91 express toll facility has, at times, provided free use by three-or-more $(\mathrm{HOV}-3+)$ people, but has also at other times required partial toll payment by these users in the past eight years of operations. Although SR-91 is the only ETL facility currently in operation, ETL concepts are more attractive than HOT lanes for those transportation agencies seeking enhanced sources of revenue and ease of enforcement.

As $M L$ are considered throughout more than 25 North American cities, there is a need for research and guidance in defining the role of carpools in tolled $M L$ and the trade-offs between carpool exemptions and other project objectives. Increasingly, project objectives are reflecting not only mobility concerns but funding deficiencies and the need to generate revenue. As a result, allowing exempt users such as carpools requires an evaluation of revenue impacts as well as mobility interests such as person movement, operations, and emissions.

\section{Carpooling and HOV Lanes}

HOV lanes and carpooling have an overlapping purpose: Encourage greater person throughput through greater vehicle occupancies. By encouraging people to rideshare, particularly during peak periods, person throughput on congested corridors can increase without a corresponding significant increase in capacity. Since the 1970s, HOV lanes have been implemented with the explicit purpose of encouraging the formation of new carpools and enhancing the performance of transit through a significant, reliable travel-time incentive.

\section{Carpool Formation}

Although distinction is made between regular carpools (recurring, scheduled carpools) and occasional carpools (situational carpools only), the basics of carpooling 
has remained the same for 60 years - a minimum of two people with common commute patterns share one vehicle for their trip. Carpooling itself requires no public investment, as the decision to carpool remains a private one. However, advocates for governmental and commercial encouragements to carpool rationalize that, "Every person added to a carpool means another congestion- and pollution-causing car is taken off the road" (The Rideshare Company 1999). As practice holds, if commuters are presented a large enough incentive to switch from driving alone to carpooling, they may form a carpool either formally (through a matching service and/or agreement) or causally (through situational agreement).

Ridematching serves as the basis for formal carpooling and has been actively conducted for 30 years. Deployed at either regional or employer levels, formal programs may be administered by employers, transit organizations, or rideshare agencies, with overlap common. For example, a regional rideshare program may offer promotional activities and incentives through participating employers. Commuters provide information to the rideshare agency that assists in matching riders together, such as work hours, vehicle availability, location of residence, and location of employment if in the case of a nonemployer rideshare program. Typically, successful formal carpooling depends on a similar employment destination, so areas with high employment densities are more aptly suited to carpool promotions than those areas with dispersed employment (Turnbull, Turner, and Lindquist 1995; Department of Environmental Quality 2000; Best Workplace for Commuters 2005). Successful ridesharing occurs only when a variety of factors are met: potential riders should:

1. live near each other,

2. travel a sufficient distance to work so that the time required for pick up and drop off does not significantly add to the total commute time,

3. either work together or within a short distance of one another,

4. have agreeable working hours to carpool schedules, and

5. have consistency in use of carpools (Turnbull, Turner, and Lindquist 1995; Department of Environmental Quality 2000).

Casual or "slugging" carpool formations began in the late 1970s and have since emerged in Virginia, California, and Texas. Not officially administered or sanctioned by governmental entities, slugging involves drivers picking up a random carpool partner to access HOV lanes at preidentified locations (Burris and Winn 2006; Slug-Lines.com 2005). Casual carpooling avoids prearrangement and fixed 
schedule hassles of formal carpooling, but does add a layer of uncertainty and risk for drivers and riders alike (Environmental Defense 2002).

Studies have shown there are three main reasons commuters switch from driving alone to ridesharing (either carpools or vanpools):

- Travel time. Research indicates that commuters are likely to alter their commute choice if it reduces their commute time. As driving alone is typically the quickest means from home to work (or the reverse), total travel time is one factor that makes driving alone attractive to drivers (Turnbull, Turner, and Lindquist 1995; Crain and Associates 1978; Valdez and Arce 1990; Cervero and Griesenbeck 1998). HOV lanes have been shown to reduce travel time, thereby making carpooling more appealing and counteracting the disposition toward driving alone (Cervero and Griesenbeck 1998; Bullard 1991; Turnbull 1992a).

- Convenience. Studies have also confirmed convenience is a factor in determining mode choice. Driving alone is seen as the most convenient mode for many commuters. However, this can change if employers or municipalities have carpooling incentives in place, making carpooling more suitable for their needs, such as conveniently located parking spaces reserved for carpoolers (Turnbull, Turner, and Lindquist 1995; Crain and Associates 1978; Valdez and Arce 1990; Cervero and Griesenbeck 1998; Turnbull 1992b; Strgar-Roscoe-Fausch, Inc. 1995).

- Cost. Although many commuters do not use the most cost-effective commute choice, it is an influential factor. Cost savings can be realized simply through the sharing of costs between driver and passenger(s), although additional financial incentives and subsidies may be offered by governmental and/or employer entities. This is especially true with vanpool programs (Cervero and Griesenbeck 1998; Turnbull 1992b; Strgar-Roscoe-Fausch, Inc. 1995). Researchers note that free or low-cost parking tends to influence a greater use of single-occupant vehicles (SOV; Turnbull 1992b).

\section{Effectiveness of HOV Incentives}

\section{Benefits}

Benefits from carpooling, which HOV lanes endeavor to encourage, can be articulated for both users and society. 
User benefits include personal cost savings and perceived quality-of-life enhancements. Many commuters underestimate the true cost of driving alone to and from work. The cost of commuting may be significantly reduced when carpoolers or vanpoolers share the costs. This is especially true in situations with added costs, such as parking fees and tolls, in addition to fuel (Model Transportation Demand Management Program 1996; Littman 2005). Commutes are increasingly becoming too congested and stressful, which can be carried over into professional and social situations. Carpooling enables riders to relax and allows them to arrive at their destination without the stress of driving (Model Transportation Demand Management Program 1996; Pollution Probe 2001).

Societal benefits are most typically associated with reduction in vehicular use (and corresponding reduction in VMT) and a resulting improvement in air quality. In areas of serious air quality concerns, carpooling and HOV lanes together constitute important elements in achieving conformity with air quality targets (Committee for the Congestion Mitigation and Air Quality Improvement Program 2002). Coupled with the perception of HOV lanes and carpooling as enabling broader environmental objectives (including fuel consumption goals), a significant stakeholder community has been formed around their continued use and promotion (Fuhs and Obenberger 2002).

\section{Effectiveness of Incentives}

Although air quality benefits are the primary reason for regional and statewide financial investment in rideshare incentive programs (most notably, through the Congestion Mitigation and Air Quality [CMAQ] program), the benefits' estimation for conformity purposes lacks consistent application throughout the United States. Communities may directly model trip-reduction and VMT-reduction benefits of ridesharing and HOV lanes, produce estimates off-model, or directly measure the results of implemented programs (Committee for the Congestion Mitigation and Air Quality Improvement Program 2002). Altogether, the variety of estimation methodologies yields a noticeable lack of measurement of the direct benefits of ridesharing on air quality. Various research efforts have attempted to evaluate the pollutant and travel reduction effectiveness of HOV incentives (including HOV lanes), but this research has yet to provide solid evidence of the longitudinal impacts of these incentives either on a regional or sitewide scale-a factor which may be important in the consideration of HOV benefits for managed lanes. 
As evaluated within the literature, the effectiveness of rideshare incentives depends on the following factors:

- type and degree of incentive,

- affected area, and

- extent of concurrent supporting strategies.

The type and degree of incentive pertains to what strategy is deployed and how much resources are applied to that strategy. For the affected area factor, the effectiveness of a strategy will differ depending on the comparative scale-an extremely successful employer-based vehicular-reduction program may not even be measurable within a half-mile radius of the employer. As evaluated in the literature, almost all programs have less than a 1 percent affect on regional tripmaking (Cambridge Systematics, Inc. 2000; Ferguson 2000). In regard to the third factor, the effects of HOV incentive programs are not mutually exclusive from one another. Often, a combination of strategies is present when modal use is measured, complicating the isolation of strategies for effectiveness.

Two cross-cutting efforts serve as the principal body of knowledge regarding HOV incentive effectiveness-one in 1994 and the other in 2002 (Committee for the Congestion Mitigation and Air Quality Improvement Program 2002; Apogee Research, Inc. 1994).

The former study involved a bounty of data primarily accumulated by the State of California during a period of mandated trip reduction efforts. The results of this data analysis were used to create a post-process model for the Federal Highway Administration (FHWA), known as the TDM Model. To this day, the TDM Model remains the only official model for evaluating the regional impacts of various rideshare promotion and incentive activities, including HOV lanes (although subsequent models from the Environmental Protection Agency and Center for Urban Transportation Research have addressed work site and subarea evaluation of TDM). However, since the early 1990s, all states with the exception of Washington have eliminated the use of mandated commute trip reduction programs. As a result, the effectiveness of ridesharing programs has diminished with solely voluntary adoption.

Evaluating work-site-based and regional travel data, the 1994 study concluded that rideshare incentives could potentially eliminate up to 2 percent of regional VMT and 1 percent of regional trips (if applied regionally) or up to 3 percent of VMT and 4 percent of trips when promoted at employment sites. HOV lanes 
alone can provide up to 1 percent of regional VMT reduction and 0.5 percent of regional trip reduction (Apogee Research, Inc. 1994). At first glance, it appears that rideshare incentives are more effective than HOV lanes; however, it should be noted that:

- HOV lanes' regional impact is affected primarily within particular corridors (unlike rideshare programs, which have a regional scope); and

- additional studies have identified a synergistic relationship between rideshare programs and HOV lanes, in so much that the likelihood of carpooling as a result of an HOV incentive program increases with the availability of HOV lanes (Littman 2005; Ferguson 2000; Schreffler 2004).

The 2002 study pertained to a review of data submitted by regional and statewide entities currently participating in the CMAQ improvement program. For most very large and large metropolitan areas, and some medium-sized areas, CMAQ provides a significant amount of funding for rideshare programs. Examining evaluation studies of CMAQ programs where the methodology of evaluation was considered sufficiently robust, the 2002 Transportation Research Board (TRB) study of cost effectiveness from CMAQ projects found that rideshare and TDM programs (which provide the bulk of incentives for HOV use) tend to be among the more cost-effective of CMAQ projects, yet the extent of effectiveness is cautiously positioned (Committee for the Congestion Mitigation and Air Quality Improvement Program 2002).

In a parallel assessment of CMAQ projects using data provided in the 2002 TRB report, an Arizona Department of Transportation report identifies the comparative relationship between HOV facilities and other strategies for the cost of air quality improvement. In this analysis, carpool and vanpool promotion programs, including cost subsidies and other incentives, are shown to be far more cost effective in reducing pounds of volatile organic compounds (pollutants) than HOV facilities. However, as noted in the report, the effectiveness of those rideshare and TDM programs is enhanced with the availability of HOV facilities (Schreffler 2004).

\section{Challenges}

Since the 1980s, when earnest planning for HOV lanes was taking place throughout the country, carpooling itself has declined significantly, both in absolute numbers of commuters as well as in percentage of overall population (Bureau of 
Transportation Statistics 2005). As shown in Table 1, declines have occurred consistently as measured by the Bureau of Transportation Statistics.

\section{Table 1. National Principal Means of Transportation to Work (person trips, thousands)}

\begin{tabular}{|l|c|c|c|c|c|c|c|}
\hline & $\mathbf{1 9 8 5}$ & $\mathbf{1 9 8 9}$ & $\mathbf{1 9 9 3}$ & $\mathbf{1 9 9 7}$ & $\mathbf{1 9 9 9}$ & $\mathbf{2 0 0 1}$ & $\mathbf{2 0 0 3}$ \\
\hline $\begin{array}{l}\text { Drive } \\
\text { alone }\end{array}$ & $\begin{array}{c}72,137 \\
(72.4 \%)\end{array}$ & $\begin{array}{c}81,322 \\
(76.3 \%)\end{array}$ & $\begin{array}{c}79,449 \\
(76.6 \%)\end{array}$ & $\begin{array}{c}90,207 \\
(77.5 \%)\end{array}$ & $\begin{array}{c}92,363 \\
(78.2 \%)\end{array}$ & $\begin{array}{c}93,942 \\
(78.2 \%)\end{array}$ & $\begin{array}{c}91,607 \\
(79.4 \%)\end{array}$ \\
\hline HOV (all) & 14,011 & 12,621 & 11,852 & 11,701 & 11,104 & 11,644 & 10,057 \\
& $(14.0)$ & $(11.8)$ & $(11.4)$ & $(10.1)$ & $(9.4)$ & $(9.7)$ & $(8.7)$ \\
\hline HOV-2 & 10,381 & 9,708 & 9,105 & 9,294 & 8,705 & 9,036 & 7,866 \\
& $(10.4)$ & $(9.1)$ & $(8.8)$ & $(8.0)$ & $(7.4)$ & $(7.5)$ & $(6.8)$ \\
\hline HOV-3 & 2,024 & 1,748 & 1,684 & 1,526 & 1,454 & 1,635 & 1,351 \\
& $(2.0)$ & $(1.6)$ & $(1.6)$ & $(1.3)$ & $(1.2)$ & $(1.4)$ & $(1.2)$ \\
\hline HOV-4+ & 1,606 & 1,165 & 1,063 & 881 & 945 & 973 & 840 \\
& $(1.6)$ & $(1.1)$ & $(1.0)$ & $(0.8)$ & $(0.8)$ & $(0.8)$ & $(0.7)$ \\
\hline
\end{tabular}

Source: Bureau of Transportation Statistics 2005.

Critics of HOV lanes claim carpooling as a choice of mode of travel for work peaked at the time when HOV-lane planning hit its stride, thereby exacerbating the rationale for continuing to offer HOV-lane incentives to carpools. Potential reasons for the decline in carpooling may include an increase in disposable income, increase in car ownership, dispersed employment locations, trip-chaining, and availability of in-car entertainment (Poole and Balaker 2005).

This criticism is valid from the perspective of home-based-work (HBW) trips, which is the type of data provided by the Census. In a comprehensive side-byside analysis of Journey to Work (Census) and National Household Travel Survey (NTHS) data, however, one author identifies distinctions between HBW trips and what was called "work tour" trips, a term which attempts to aggregate trip chaining into one consolidated work trip (as the primary purpose). Using 2001 NHTS data, approximately 20 percent of work tours (trips that are not simply HBW trips, but rather also involves a pick-up or drop-off at some point between home and work) and only 12 percent of commute trips were by carpool (McGuckin and Srinivasan 2005). This indicates there is a greater percentage of the population that uses carpool modes for the work trip (meaning, these are not HBW trips, as the 
trip involves a pick-up or drop-off at some point between home and work). What this research does not indicate, however, is what proportion of the work trip is as a carpool. Further investigation into current carpooling trends indicates that the majority of carpools are family oriented, a type of carpooling termed "fam-pools" (Poole and Balaker 2005). Only 26 percent of all 2001 work tour carpools involved a nonhousehold member, compared to 74 percent involving a family member.

Critics have argued that the extensive amount of household-member-only carpooling for work trips belies the premise behind investments in HOV lanes-that it will encourage the formation of carpools between two drivers, explicitly to take advantage of the travel time savings in the HOV lanes:

That fampooling does not take cars off the street is particularly evident when HOV lanes are used by drivers whose passenger is someone who, for a variety of reasons, would not be driving anyhow. For example, it is certainly convenient for a parent driving with a son or daughter to use the carpool lane, but as long as the son or daughter is under the legal driving age, this sort of carpool does not spare the road from an extra car. (Poole and Balaker 2005)

Fam-pooling criticism implies that family members who carpool would do so with or without the presence of HOV lanes and other incentives. However, counterargument suggests that familial carpools (particularly involving two or more adults) are perfectly legitimate to the extent those family members would otherwise drive separately.

Regions with significant HOV facility investments have not been immune to declines in carpool rates. In Southern California, representing the greater Los Angeles metropolitan region, carpooling as a share of work trips declined from 14.3 percent to 11.4 percent since 2000, despite the availability of more than 350 route miles of HOV lanes (Chang 2005; Fuhs 2005). Similarly, the San Francisco Bay Area, with more than 150 route miles of HOV lanes, declined from a peak of 19 percent of commuters by carpool in 1995 to 14 percent in 2005 (Fuhs 2005; RIDES for Bay Area Commuters 1998; RIDES Associates 2005). Ideally, ML operators will evaluate HOV use effectiveness per facility (reflecting localized demand); however, the emerging context of regional policy making for $\mathrm{ML}$ (as evidenced by efforts in the Bay Area, Puget Sound region, Dallas/Ft. Worth area, and others) indicates that regional metrics will be as important as localized metrics. 


\section{The State of the Practice in Applying Carpool Incentives to $\mathbf{M L}$}

Given the evolution of HOV facilities to ML over the last decade and the level of activity in development of $M L$ projects nationally, there is still very little in the way of research and guidance defining the role of carpools and the trade-offs between carpool preference and other project objectives. A study of HOV treatments on toll facilities concluded that HOV pricing strategies and priority treatments are being utilized on a variety of toll facilities in the United States, although information on utilization levels and mode choice influences were very limited (Turnbull 1994). In examining the ML projects in operation today, decisions related to carpool preference have been based largely on policy decisions with little basis in quantitative analysis (Collier and Goodin 2004).

To obtain a current picture of HOV policies on ML facilities-both active and pending implementation-state and regional agencies involved with ML were contacted in January and February 2006 (Denver's project opened in June 2006, so it is reported as an "active" facility, although at the time of interview, it was still pending). Each responding entity, aggregated by region, compiled their communities' interests and pursuits regarding HOVs.

\section{Overview of Metropolitan Areas}

Figure 1 provides an overview of the various regions' approaches toward the tolling of HOVs on ML facilities. Note that the San Francisco Bay Area is different from the other implementations in that HOV discounts are applied on toll bridges with HOV lanes feeding the bridges. Although this is not a ML under conventional definitions, the resulting travel time and toll advantages on the HOV user proxies the effect of $M L$; hence, they are included in this analysis.

As shown in Figure 1, a few patterns emerge from the responses:

- All facilities toll or intend to toll SOVs. Houston has been the only community that has experimented with HOV-2 tolling, with no access to SOVs by toll. However, the reconstruction of the HOV facility on I-10 (opening 2008/2009) will provide sufficient capacity to permit tolled access to both HOV-2 and SOV.

- Most facilities provide free access to HOV-3+. The only exceptions to this policy are Orange County, California (where demand on the 91 Express Lanes is sufficiently high in the eastbound direction to require a discount toll in the PM peak period instead of free passage); Denver's (Colorado) C-470 


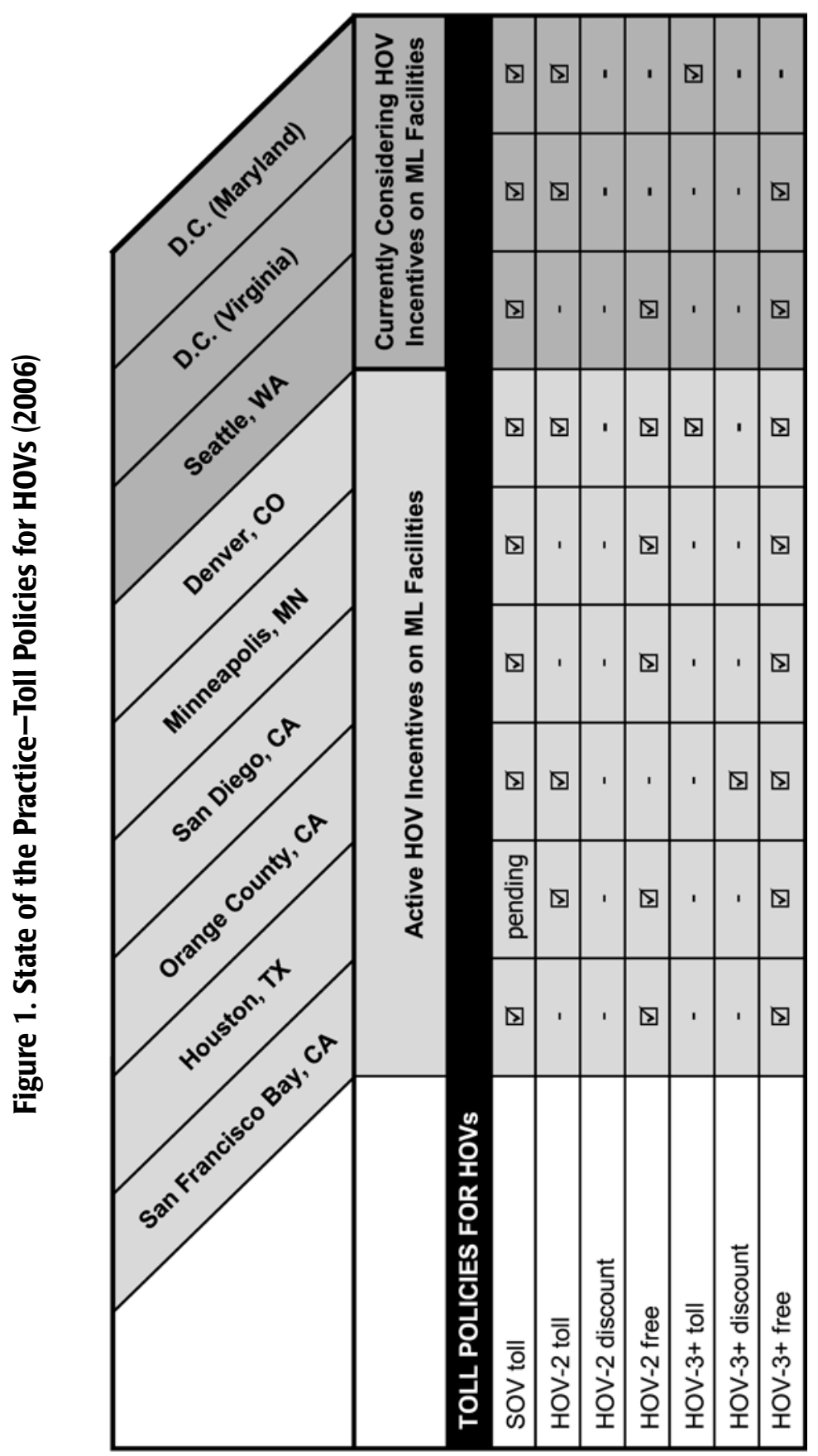


Express Lanes (for which HOV-3+ policies have not yet been finalized, but environmental documentation indicated all vehicles may be tolled regardless of occupancy); and Maryland (which intends to toll all vehicles on $\mathrm{ML}$ statewide without regard to occupancy).

- In general, HOVs either pay the full toll or travel toll free. Only one facility, the 91 Express Lanes, pursues a half-toll policy for HOVs. No other facility featured in the surveyed communities has adopted or intends to adopt a similar policy for either HOV-2 or HOV-3+.

- Most communities have a standard HOV toll policy. With the exception of the Denver area, where the $\mathrm{I}-25$ and $\mathrm{C}-470$ facilities provide differential rates and access to HOV-2 and HOV-3+, and the D.C. area, where Maryland and Virginia will have different HOV toll policies, all other communities generally have standardized their HOV toll policies across the region-either by intent or by default.

Figure 2 offers each region's responses to factors potentially impacting regional and/or corridor decisions for HOV-2 or HOV-3+ toll policies. These factors may be constituted in official transportation policy or may reflect prevailing concerns of agency stakeholders in the development of $M L$ facilities per region. The scale for each factor is rated simply as "high importance," "moderate importance," and "low importance" in terms of its effects on decision making in the region.

Unlike the toll policies, these results do not lend themselves easily to overall trends. Two principal findings include:

- No factor uniformly rates as a high or low importance in regional decision making. This finding confirms that each region is different and has its own core issues to address in setting ML policies. Furthermore, the different importance values assigned to each factor suggests that nationally standardized criteria regarding HOV toll policies not only do not exist but are also inappropriate, relative to regional issues.

- Factors that rate consistently high or moderate across all corridors and/or regions include: enforcement of carpool vehicles, maximizing vehicular throughput, and uniformity/equity issues. The first two factors are invariably linked to one another. Ensuring adequate enforcement of carpool policies without cumbersome geometric solutions may help fulfill the objective of maximizing vehicular throughput. With enforcement, pricing responds directly to prevailing demand; without adequate enforcement, pricing must 


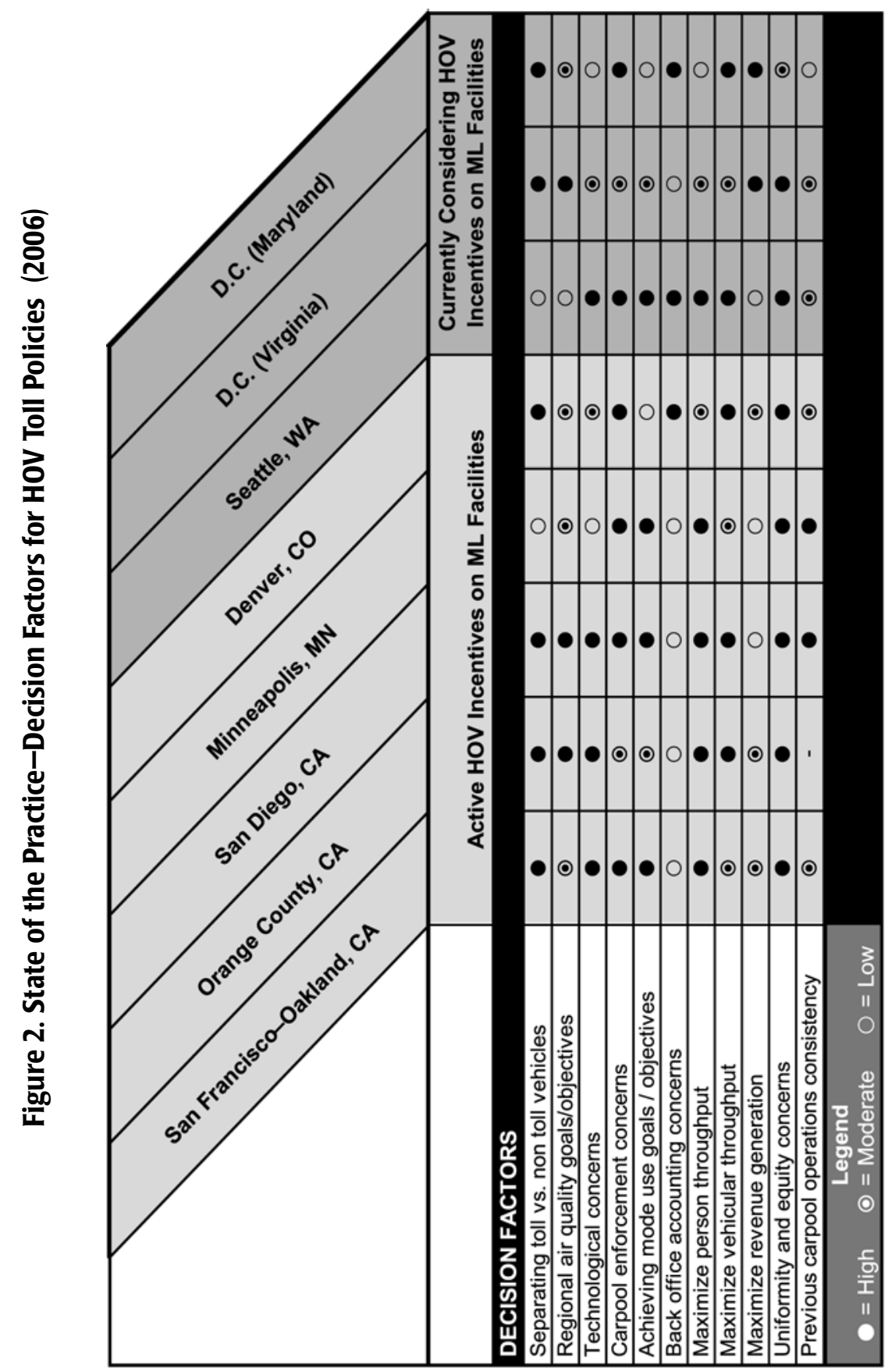


also account for violators, which distorts the price of entry. The final factors, uniformity and equity, suggest a policy issue that is rarely quantified in HOV preference: offering an HOV incentive not for air quality or modal use purposes, but rather to provide a toll-free alternative for potentially disadvantaged communities that is still consistent with regional transportation objectives.

\section{Conclusions}

Overall, the application and objectives of incentives for carpools in ML facilities differs widely across the United States. Although a nexus is found between the use of incentives (including cost incentives and other TDM activities) and HOV-lane usage, the evidence for priced $M L$ is less clear. Furthermore, when considering the effectiveness of carpool incentives relative to the decline in "acquaintance" carpools (as opposed to family carpools), policy-makers would be well advised to consider the overall contribution of incentives to the expressed objectives of the program.

The regional and state agencies interviewed for this research were consistent in rating high only a few guiding principles for carpool incentives: enforcement of carpool vehicles, maximizing vehicular throughput, and uniformity/equity issues. These three issues are generally considered outside the realm of consideration of TDM programs, whereby carpool incentives are initially set-these typically include air quality, person mobility, and accessibility to employment. This implies a disconnect between the expressed purpose of carpool programs on a regional basis, and, the application of carpool incentives on ML facilities. As regional planning processes consider the appropriate role of carpools on $M L$, efforts should be made to connect the objectives of regional demand management programs directly with policies as applied on ML.

\section{Acknowledgments}

The authors would like to thank the Texas Department of Transportation (TxDOT) for sponsorship of the research on which this article is based. The research was performed by the Texas Transportation Institute of the Texas A\&M University System and the University of Texas at Arlington. The contents of this article reflect the views of the authors, who are responsible for the facts and the accuracy of the 
data presented herein. The contents do not necessarily reflect the official views or polices of the Federal Highway Administration or TxDOT.

\section{References}

Apogee Research, Inc. 1994. Cost and effectiveness of transportation control measures (TCMs): A review and analysis of the literature. (January).

Best Workplace for Commuters. 2005. Carpool incentive programs: Implementing commuter benefits as one of the nation's best workplaces for commuters. U.S. Environmental Protection Agency, Office of Air and Radiation. (March). http://www.bwc.gov/pdf/carpool.pdf.

Bullard, D. L. 1991. An assessment of carpool utilization of the Katy high-occupancy vehicle lane and the characteristics of Houston's HOV lane users and nonusers. College Station, TX: Texas Transportation Institute.

Bureau of Transportation Statistics. 2005. National transportation statistics: 2005. U.S. Department of Transportation, 2005. http://www.bts.dot.gov/publications/national_transportation_statistics/2005/.

Burris, M. W., and J. R. Winn. 2006. Slugging in Houston-Casual carpool passenger characteristics. Journal of Public Transportation 9 (5).

Cambridge Systematics, Inc. 2000. Quantifying air quality and other benefits and costs of transportation control measures. Final Report. NCHRP Project 8-33.

Cervero, R., and B. Griesenbeck. 1998. Factors influencing commuting choices in suburban labor markets: A case study of Pleasanton, California. Transportation Researcher 22A (3): 151-161.

Chang, P. 2005. State of the region 2005: Measuring regional progress. Southern California Association of Governments. (December). http://www.scag.ca.gov/ publications/pdf/2006/SOTR05/SOTR05_FullReport.pdf.

Collier, T., and G. Goodin. 2004. Managed lanes: A cross cutting study. FHWA-HOP05-037. McLean, VA: Federal Highway Administration. (November).

Committee for the Congestion Mitigation and Air Quality Improvement Program. 2002. The congestion mitigation and air quality improvement program: Assessing 10 years of experience. Special Report 264. Transportation Research Board, National Academy Press. 
Crain and Associates.1978. San Bernardino freeway busway evaluation of mixedmode operations. Los Angeles, CA: California Department of Transportation.

Department of Environmental Quality. 2000. Guidance for estimating trip reductions from commute options. http://www.deq.state.or.us/NWR/ECO/checklst.pdf.

Environmental Defense. 2002. What are casual carpools? (February 11). http:// www.environmentaldefense.org/article.cfm?ContentID $=1363$.

Ferguson, E. 2000. Travel demand management and public policy. Burlington, VT: Ashgate Publishing Co.

Fuhs, C. 2005. Operational characteristics of selected freeway/expressway HOV facilities. Transportation Research Board HOV Systems Committee. (December). http://www.hovworld.com/hovinventory_assets/Hov\%20Operations\%201121-05.pdf.

Fuhs, C., and J. Obenberger.2002. HOV facility development: A review of national trends. Transportation Research Board HOV Systems Committee. (January). http://www.hovworld.com/PDFs/Fuhs_Obenberger-final\%20paper.pdf.

Littman, T. 2005. TDM encyclopedia: Ridesharing. Victoria Transport Policy Institute.(December 14). http://www.vtpi.org/tdm/tdm34.htm.

McGuckin, N., and N. Srinivasan. 2005. Journey to work in the context of daily travel. Transportation Research Board, Census Data for Transportation Planning Conference (May). http://www.trb.org/conferences/censusdata/ResourceJourney-to-Work.pdf.

Model Transportation Demand Management Program. 1996. Explore your commute options: It's the SMART thing to do. Detailed Program Description and Policy Guidelines. Washington State Department of Transportation. (June). http://www.wsdot.wa.gov/tdm/tripreduction/download/CTR_Manual.pdf.

Pollution Probe. 2001. SMART movement: Save money and air by reducing trips. Trip Reduction Manual. http://www.pollutionprobe.org/Reports/SMART.pdf.

Poole, R., and T. Balaker. 2005. Virtual exclusive busways: Improving urban transit while relieving congestion. Reason Foundation, Policy Study 337 (September). http://www.reason.org/ps337.pdf.

RIDES Associates. 2005. Commuter profiles 2005: Regional report. Metropolitan Transportation Commission (June). http://www.mtc.ca.gov/library/commute_profile/commuteprofile_2005.pdf. 
RIDES for Bay Area Commuters. 1998. Commuter profile 1998. Metropolitan Transportation Commission. http://www.mtc.ca.gov/library/commute_profile/commuteprofile_1998.pdf.

The Rideshare Company. 1999. Carpools a simple way to save time, money and the environment. http://www.commutersregister.com/ct/articles/9905/rslocal. htm.

Schreffler, E. 2004. Alternative modes as an air quality mitigation strategy. Report No. FHWA-AZ-04-566. (June). http://ntl.bts.gov/lib/24000/24800/24853/ AZ566.pdf.

Slug-Lines.com. 2005. About slugging. http://www.slug-lines.com/Slugging/ About_slugging.asp.

Stockton, W. R., G. Daniels (Goodin), D. Skowronek, and D. Fenno. 1999. The ABC's of HOV: The Texas experience. Texas Transportation Institute, Texas A\&M University. (September). http://www.hovworld.com/PDFs/1353-I.pdf.

Strgar-Roscoe-Fausch, Inc. 1995. I-394 phase III evaluation-final report. Minneapolis, MN: Minnesota Department of Transportation.

Swisher, M., W. Eisele, D. Ungemah, and G. D. Goodin. 2002. Life cycle graphical representation of managed HOV lane evolution. Committee on High Occupancy Vehicle Systems, 11th International HOV Conference. (October). http:// www.hovworld.com/PDFs/TRB2003-002138.pdf.

Turnbull, K. F. 1992a. An assessment of high-occupancy vehicle facilities in North America: executive report. College Station, TX: Texas Transportation Institute.

Turnbull, K. F. 1992b. High-occupancy vehicle project case studies: Historical trends and project experience. College Station, TX: Texas Transportation Institute.

Turnbull, K. F. 1994. High-occupancy vehicle (HOV) treatments on toll facilities. Transportation Research Record 1446.

Turnbull, K. F., P. A. Turner, and N. F. Lindquist. 1995. Investigation of land use, development, and parking policies to support the use of high-occupancy vehicles in Texas. College Station, TX: Texas Transportation Institute.

Valdez, R., and C. Arce. 1990. Comparison of travel behavior and attitudes of rideshare, solo drivers, and the general commuter population. Transportation Research Record 1285: 105-108. 


\section{About the Authors}

David Ungemah (d-ungemah@tamu.edu) has 13 years of experience in TDM and ML. Prior to joining the Texas Transportation Institute in 2005, Mr. Ungemah cofounded UrbanTrans Consultants, a firm specializing in TDM services. He received his undergraduate degree in political science from the University of Colorado and master of planning from the University of Minnesota. Mr. Ungemah is an active member of the TDM and Congestion Pricing committees of the Transportation Research Board, and currently chairs the HOV/HOT Council for the Association for Commuter Transportation.

GiNGer Goodin (g-goodin@tamu.edu) has more than 20 years of experience in transportation engineering and planning, with specialty in HOV and ML systems. She received both her undergraduate and graduate degrees in civil engineering from Texas A\&M University. Ms. Goodin currently serves as chair of the HOV Systems committee of the Transportation Research Board.

MARK BURRIS (mburris@tamu.edu) is an assistant professor in the Department of Civil Engineering at Texas A\&M University, and an assistant research scientist at the Texas Transportation Institute. He received his bachelor of engineering, co-op program, degree in 1993 from the Technical University of Nova Scotia, his master of science in engineering in 1995 from the University of New Brunswick, and his doctorate in civil engineering in 2001 from the University of South Florida. Prior to joining Texas A\&M in August 2001, he was a senior research associate at the Center for Urban Transportation Research (CUTR) in Tampa, Florida.

CASEy Dusza (c-dusza@tamu.edu) has served as an assistant transportation researcher at the Texas Transportation Institute for five years. She received her undergraduate degree in community and regional planning from lowa State University and her graduate degree in community and regional planning from the University of Texas. Mrs. Dusza is active in a variety of research projects including those focusing on TDM, ML, and bicycle issues. 